\title{
Prevalence of gastrointestinal parasites and Cryptosporidium species in extensively managed pigs in Mekelle and urban areas of southern zone of Tigray region, Northern Ethiopia
}

\author{
Zewdneh Tomass ${ }^{1}$, Ekwal Imam" ${ }^{1 \#}$ Tsegabirhan Kifleyohannes ${ }^{2}$, Yohannes Tekle ${ }^{2}$ and Kidane Weldu ${ }^{2}$ \\ 1.Department of Biology, College of Natural and Computational Sciences, Mekelle University, Ethiopia (Africa); \\ 2.College of Veterinary Medicine, Mekelle University, Ethiopia (Africa); \#Association with Department of Wildlife \\ Sciences, AMU, Aligarh, India. \\ Corresponding author: Ekwal Imam, E-mail: ekwalimam01@gmail.com \\ Received: 03-11-2012, Accepted: 22-11-2012, Published online: 30-04-2013
}

How to cite this article: Tomass Z, Imam E, Kifleyohannes T, Tekle Y and Weldu K (2013) Prevalence of gastrointestinal parasites and Cryptosporidium spp. in extensively managed pigs in Mekelle and urban areas of southern zone of Tigray region, Northern Ethiopia, Vet World 6(7):433-439, doi: 10.5455/vetworld.2013.433-439

\begin{abstract}
Aim: The objective of this study was to investigate prevalence of gastrointestinal parasites and Cryptosporidium species in extensively managed pigs in Mekelle and urban areas of southern zone of Tigray Region, Ethiopia during June - September, 2012.

Material and methods: Seven hundred fourteen pigs of different ages and sexes were selected for fecal sample collection. Fecal samples were collected from the rectum of pigs with strict sanitation. A total of 25 soil samples were also collected from backyards of pig pens using clean zipped plastic bags. Both fecal and soil samples were examined for eggs and cysts of GIT parasites by flotation and sedimentation techniques. Modified Ziehl - Neelsen technique was used to examine oocysts of Cryptosporidium species from 276 randomly selected fecal samples.

Results: Out of 714 pigs examined through flotation and sedimentation, $27.3 \%$ were infected by at least one gastrointestinal parasite. Ascaris suum (25.9\%) was the most prevalent parasite followed by Fasciola hepatica (1.8\%), Eimeria spp. (1.7\%) and Trichuris suis $(0.3 \%)$. There was no significant association between sex and prevalence of parasites $\chi^{2}[\mathrm{df} 1]=1.921$; $P=0.166$ ). Contrary to this, age of pigs had effect on prevalence of parasites $\chi^{2}[\mathrm{df} 2]=8.376 ; P=0.015$ ). About $7 \%$ of pigs examined were positive for oocysts of Cryptosporidium spp. Moreover, $72 \%$ of the soil samples found to be contaminated with eggs of Ascaris spp. in the study area. Apart from causing morbidity in the infected pigs, the potential of Ascaris of pigs to infect man and vice versa together with poor environmental hygiene, may complicate the epidemiology and control of Ascariasis in the study areas. Extensively managed pigs may also act as potential reservoirs for zoonoses of Cryptosporidium species.
\end{abstract}

Conclusion: It is concluded that further investigations are crucial on molecular characterization of Ascaris and Cryptosporidium isolates of extensively managed pigs to determine the parasites upto species level so as to suggest proper control strategies.

Keywords: Ascaris spp., Cryptosporidium spp., Ethiopia, extensive pig management, gastrointestinal parasites, Mekelle, Tigray Region

\section{I ntroduction}

Infection of pigs with gastrointestinal (GIT) parasites is widely reported from all corners of the world and shown to be influenced by the type of pig management practiced [1]. Extensive production of pigs for commercial purpose is widely practiced in developing countries of Africa. Availability of cost free feed (household or municipal garbage) and possibilities for the animals to get better nutrition through scavenging initiate pig growers of developing countries to prefer extensive management. In this regard $70-95 \%$ of pig raising sectors of developing countries practice extensive husbandry [2].

Poor environmental hygiene coupled with extensive managements is reported as risk factors of

This article is an open access article licensed under the terms of the Creative Commons Attribution License (http://creativecommons. org/licenses/by/2.0) which permits unrestricted use, distribution and reproduction in any medium, provided the work is properly cited. infection of pigs with GIT parasites [1]. Gastrointestinal helminths including Oesophagastomum dentatum, Trichuris suis, Ascaris suum, Oesophagastomum quadrispinulatum, Trichostrongylus axei, Strongyloides ransomi, Hyostrongylus rubidus and Physocephalus sexalutus have been identified in pigs raised under extensive production in Kenya, Ghana and Burkina Faso [3-5]. Semi-extensively managed pigs are reported to harbor Taenia solium, in Nigeria [6]. Pigs rose under semi-intensive and extensive husbandry were found to be infected with Ascaris suum and Oesophagostomum spp. in Holeta, Ethiopia [7]. In addition to helminths, extensively managed pigs are also reported to harbor intestinal protozoans including Cryptosporidium spp., Giardia lambelia, Balantidium coli and Eimeria spp. in developing countries [8]. Among other intestinal protozoans Cryptosporidium has been given much attention because of its occurrence in various domestic and wild animals and and its potential for causing emerging cryptosporidiosis [9]. 
Cryptosporidium is a protozoan parasite belonging to Phylum Apicomplexa and family Cryptospordiidae that causes severe diarrhea, anorexia and weight loss, especially in immunocompromised animals and humans (mainly children bellow five years of age and HIV/ AIDS patients). Cryptosporidiosis is caused by several genotypes and phenotypically diverse Cryptosporidium species and has been emerging over the past decade. [9].

At present more than 22 Cryptosporidium species have been identified [9] however, over 60 genotypes remain undefined [10]. Recent genetic characterization studies revealed that pigs are infected with genetically distinct and host-adapted form of Cryptosporidium, Cryptosporidium "pig"genotype [11]. However, pigs can also be infected with the zoonotic Cryptosporidium parvum, "cattle" genotype, indicating their potential as reservoirs of zoonotic infection to humans [11].

So far Haileyesus [12], reported prevalence of Cryptosporidium parvum and $C$. hominis in extensively managed cattle and HIV/AIDS patients in Ethiopia. However, there is lack of data regarding the prevalence of Cryptosporidium spp. in extensively managed pigs in Ethiopia. Hence, it is crucial to determine the prevalence of Cryptosporidium species in pigs before classifying them as one of the reservoirs for zoonotic cryptosporidiosis in Ethiopia.

Pig infected with GIT parasites had poor feed conversion rate and delays in achievement of market weight. Some of the GIT parasites of pigs result in condemnation of organs or entire carcasses causing economic losses in pork industry [13]. In addition, pigs infected with GIT parasites may act as source of zoonoses through contaminating the environment with infective stages of intestinal parasites present in their excreta [11]. The epidemiology of pig born GIT parasites may further be complicated when some of the parasites of pigs infect man and vice versa. Ascaris spp. is typical example [14].

In Ethiopia the population of pigs has shown slight increment since 1980. However, pig raising is at its infancy in the country with a total population of about 1900 [15]. Recently small scale pig husbandry is being practiced in urban areas of Ethiopia, however, the management is mainly extensive whereby pigs are allowed to scavenge on household wastes at backyards and municipal garbage dumping sites at peri-urban areas [7]. Such extensive pig husbandry coupled with poor environmental hygiene and pigs' voracious feeding behavior may render infection of the animals with helminth and GIT parasites in Ethiopia. Nevertheless, few studies have been done on prevalence of GIT parasites in extensively managed pigs in Ethiopia in general and Tigray Region in particular [7]. Therefore, this study was initiated to investigate prevalence of GIT parasites in extensively managed pigs and associated environmental health risks in Mekelle and urban areas of southern zone of Tigray Region, Ethiopia.

\section{Materials and Methods}

Study areas: This study was carried out in Mekelle and Southern Zones of Tigray Region, Ethiopia (Fig-1). Mekelle is the capital city of Tigray Region located 780 $\mathrm{km}$ north of Addis Ababa, the capital city of Ethiopia. Its geographic location is $13^{\circ} 32^{\prime} \mathrm{N}$ and $39^{\circ} 33^{\prime} \mathrm{E}$. It has an average altitude of 2200 m.a.s.l with a mean minimum and mean maximum monthly temperatures of 8.7 and 26.8 respectively. Mekelle receives an average $600 \mathrm{~mm}$ of rainfall annually and more than $70 \%$ of it falls between July and August, followed by long dry season (October to May) [16]. Mekelle has an estimated total human population of 215,546 [17]. Urban agriculture is a common practice in Mekelle [18]. The livestock management system practiced in Mekelle includes extensive, intensive and semiintensive [19]. Pigs are recently introduced into Mekelle and raised by few households under extensive management.

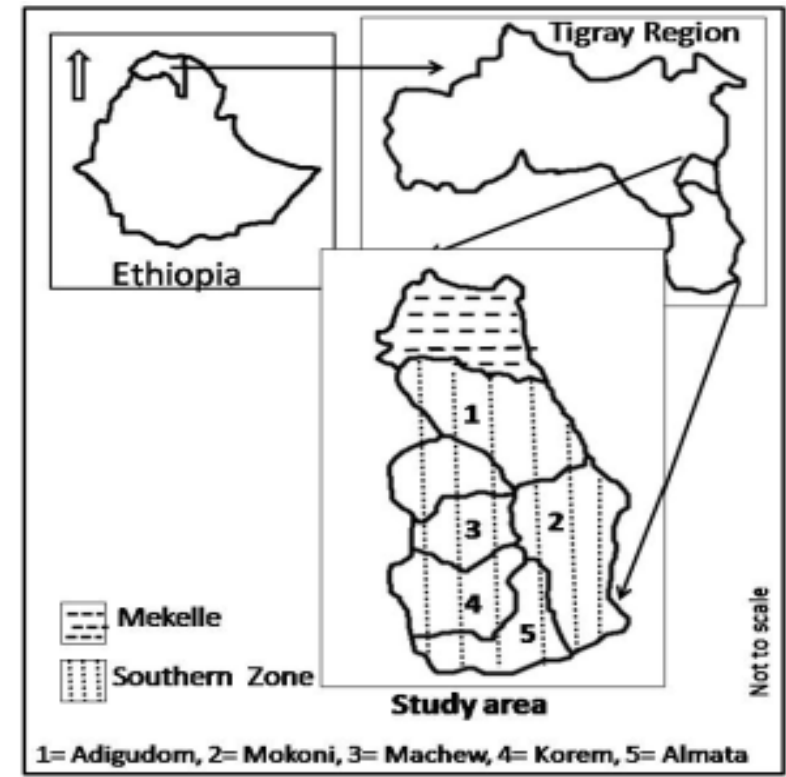

Fig.1: Map of the study area

Southern zone of Tigray Region is located in northern Ethiopia (longitude $39^{\circ} 5^{\prime}-39^{\circ} 8^{\prime}$ and latitude $12^{0} 3^{\prime}-13^{0} 7^{\prime}$ (Fig-1). Here agriculture involves mixed crop and livestock farming. The climate is characterized by bimodal rainfall. About $70-80 \%$ of the rain falls in the Kiremt season (June-September) [20]. The mean minimum and maximum temperature ranges from $8^{\circ} \mathrm{C}$ to $30^{\circ} \mathrm{C}$, with small annual variations. This zone is composed of 11 districts (Weredas). According to the 2007 census, the total urban and rural human population of the zone is estimated to be $1,004,558$ [17]. This zone includes major urban areas of Alamata, Mekoni, Korem, Maychew and Adigudom. Recently the number of households engaged in extensive pig husbandry are increasing in urban areas of southern zone of Tigray region.

Animals studied: This study was conducted during June - September 2012. Seven hundred fourteen 
Table-1. Distribution of sample pigs $(n=714)$ with respect to sex and age in Mekelle and urban areas of Southern Zone of Tigray Region, Ethiopia

\begin{tabular}{lcccc}
\hline Sex & \multicolumn{3}{c}{ Age category of pigs } & Total \\
& $<\mathbf{5}$ months & $\mathbf{5 - 1 2}$ month & $\mathbf{1 1 2}$ months & \\
\hline Male & 177 & 143 & 16 & 336 \\
Female & 163 & 154 & 61 & 378 \\
Total & 340 & 297 & 77 & 714 \\
\hline
\end{tabular}

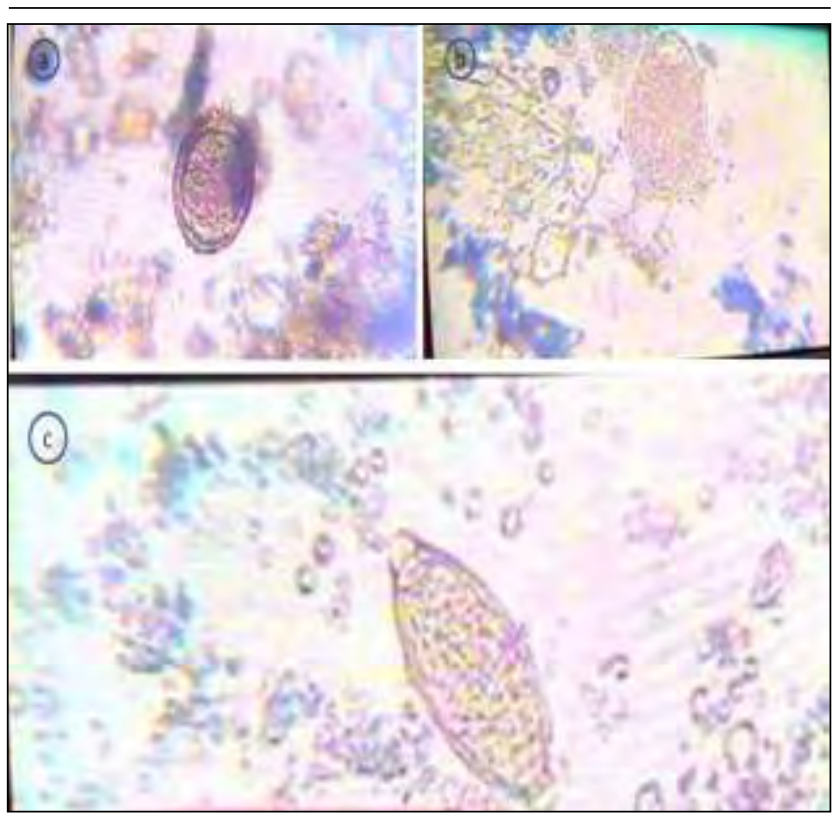

Fig.2: Eggs of gastrointestinal helminths isolated from extensively managed pigs in Mekelle and urban areas of Southern Zone of Tigray Region, Ethiopia; Ascaris suum (a), Fasciola hepatica (b) and Trichuris suis (c)

extensively managed pigs ( 336 males and 378 females) owned by a total of 38 households in Mekelle and urban areas of southern zone of Tigray Region were included in the study. On the basis of the pig owning household head's declaration, the animals were categorized into three age groups of $<5$ months old, 5-12 month old and $>12$ months old. Distribution of the pigs with respect to sex and age is given in Table-1.

Collection of fecal and environmental samples: Fecal samples were collected directly from the rectum of pigs with strict sanitation in the morning, when households release the animals from their pens. About 5 gram of the collected fecal sample was put in screw cap bottles containing $10 \%$ formalin. Soil samples were collected from backyards of pig pens using clean zipped plastic bags. Fecal and soil samples were transported to the Parasitology Laboratory, Department of Biology, Mekelle University (Ethiopia) on same day and stored at $-20{ }^{\circ} \mathrm{C}$ until processed and examined for eggs and oocysts of gastrointestinal helminths and protozoans, respectively.

Processing and examination fecal and soil samples Zinc sulphate flotation: Three grams of fecal samples were mixed with $50 \mathrm{ml}$ of $0.4 \mathrm{~g} / \mathrm{ml}$ Zinc Sulphate (flotation fluid) using mortar and pistil. Similarly soil samples were also mixed with $50 \mathrm{ml}$ of $0.4 \mathrm{~g} / \mathrm{ml}$ Zinc Sulphate. The resulting fecal or soil suspension was
Table-2. Demographic information and pig husbandry conditions practiced by households in Mekelle and Southern Zone of Tigray Region, Ethiopia

\begin{tabular}{lc}
\hline Variables & $\begin{array}{c}\text { No. (\%) pig owning per } \\
\text { households }\end{array}$ \\
\hline Sex & $38(100)$ \\
Male & $0(0)$ \\
Female & $16(42.11)$ \\
Pig raising as an occupation & $22(57.89)$ \\
Par time & \\
Full time & $38(100)$ \\
Purpose of pig raising & $0(0)$ \\
For market & \\
For food/other purpose & $32(84.21)$ \\
Tap water supply for the household & $6(15.79)$ \\
Yes & \\
No & $32(84.21)$ \\
Toilet for the household & $6(15.79)$ \\
Yes & \\
No & $12(31.58)$ \\
Damping site for pig slurry & $19(50)$ \\
Municipal garbage container & $7(18.42)$ \\
Nearby garden/farm & $6(15.79)$ \\
Municipal wastewater canal & $32(84.21)$ \\
Floor condition of pig pen & \\
Cemented/cobbled with stone & \\
None cemented /non stone cobbled & \\
\hline
\end{tabular}

poured through a tea strainer into a beaker. Then suspension was poured from the beaker into a test tube leaving a convex meniscus at the top. A cover slip was then carefully placed on top of the test tube and the test tube was let to stand for 20 minutes and after that cover slip was carefully lifted from the tube together with a drop of fluid adhering to it and immediately placed on a glass slide for microscopic examination [21]. These procedures were used to recover eggs intestinal helminths and oocysts of Eimeria spp.

Sedimentation: In case of using $\mathrm{NaCl}$ as a flotation solution, the flotation technique was supplemented with sedimentation to recover eggs of intestinal helminths such as Fasciola hepatica which do not float well in sodium chloride solution. For this purpose, $3 \mathrm{~g}$ of fecal or soil samples was put in a conical flask and mixed with $30 \mathrm{ml}$ of water; the mixture was then sieved through a tea strainer into a beaker and transferred into a centrifuge tube for centrifuging at 1500 rotation per minute for 3 minutes. The supernatant was then discarded and sediment was mixed with $1 \%$ of methylene blue and examined under the microscope using 40objective lens [22].

Modified ZiehI-Neelsen technique: A total of 276 randomly selected pig fecal samples from Mekelle and urban areas of southern zone of Tigray Region were examined for Cryptosporidium oocyts by the modified 


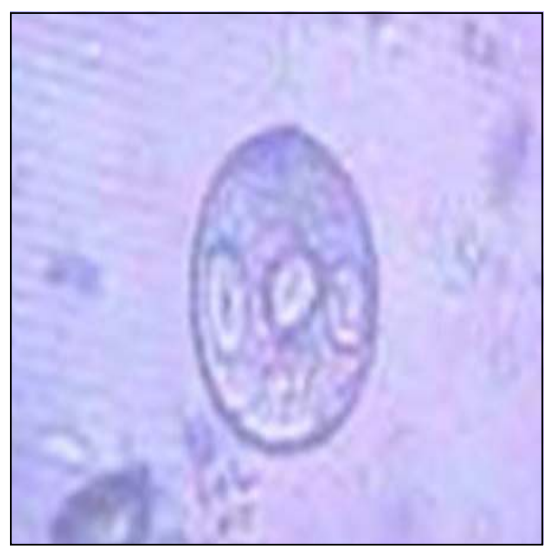

Fig.3: Oocyst of Eimeria species isolated from extensively managed pigs in Mekelle and urban areas of Southern Zone of Tigray Region, Ethiopia

Ziehl - Neelsen technique [21]. Thin fecal smear was prepared from each of the fecal samples, air-dried, fixed with absolute methanol and stained with a carbolfuchsin (primary stain) for 30 minutes. The smear was then washed with tap water and decolorized with $1 \%$ acid-alcohol ( $1 \mathrm{ml} \mathrm{HCl}$ and $99 \mathrm{ml}$ of $96 \%$ ethanol) for 2 minutes; washed again with tap water and counterstained with $1 \%$ methylene blue for another 2 minutes, then rinsed again in tap water and air-dried. The smear slides were then examined under a microscope at $1000 \mathrm{x}$ magnification for detection of Cryptosporidium oocysts.

Survey for demographic information and pig husbandry conditions: A close ended interview questionnaire containing variables including characteristics of pig owning households and demographic information was first prepared in English and then translated into the local language of Tigriyna, to collect data on pig owning households. Interviews were administered to a total of 38 household heads encountered during the study. Observational check list containing variables such as presence of toilet and tap water supply for the household, site for dumping of pig slurry and floor condition of pig pens was prepared to collect data on pig husbandry condition at household level.

Statistical analysis: Descriptive statistics was used to summarize data on prevalence of gastrointestinal parasites in pigs and contamination of soil by helminth eggs in Mekelle and urban areas of southern zone of Tigray Region, Ethiopia. Chi-square test using SPSS10 [23] software was conducted to see if there is any difference between prevalence of gastrointestinal parasites with respect to age and sex of the pigs as well as among different study sites.

\section{Results}

A total of 38 male household heads with ages ranging from 15-69 years were identified engaged in extensive pig management in Mekelle and urban areas of southern zone of Tigray Region. Pig husbandry was a fulltime occupation for about $22(58 \%)$ of the

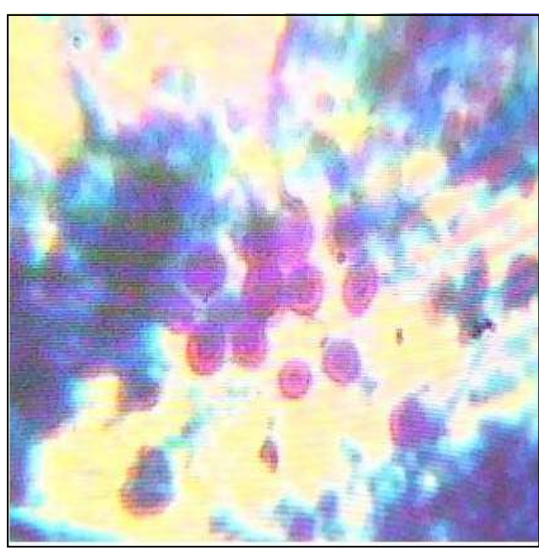

Fig.4: Oocysts of Cryptosporidium species detected from extensively managed pigs in Mekelle and urban areas of Southern Zone of Tigray Region, Ethiopia.

households. Fifty percent of the pig owning households dump slurry of the animals in the nearby agricultural farms as manure (Table-2). The mean number of family size and pigs owned by households were found to be $4.05 \pm 0.379$ and $20.82 \pm 2.89$, respectively.

Out of 714 coprological samples of pigs examined, 195 (27.3\%) were positive for at least one of the gastrointestinal parasites in Mekelle and southern zones of Tigray Region (Table-3). During microscopic examination $169(94.94 \%), 05(2.81 \%)$ and $01(0.56 \%)$ pigs were found to be positive for eggs of Ascaris suum, Fasciola and Trichuris suis respectively (Fig. 2).

On the other hand, $3(1.69 \%)$ pigs were found to be positive for oocysts of Eimeria spp. (Fig. 3, Table 4). About 26\% of the parasitized pigs were infected with A. suum either as a single or multiple infections with other parasite species. However, there is no statistically significant association in the prevalence of intestinal parasites in pigs between Mekelle zone and southern zone of Tigray Region ( $\chi^{2}[\mathrm{df} 1]=0.320 ; P=0.572$ ). There is also no association in the prevalence of parasites between male and female pigs in the study areas $\left(\chi^{2}[\mathrm{df} 1]=1.921 ; P=0.166\right)$. On contrary, there is significant association between different age categories and prevalence of parasites, where majority of infection occurring in pigs with ages ranging from 512 months ( $\left.\chi^{2}[\mathrm{df} 2]=8.376 ; P=0.015\right)$.

Moreover, Out of 276 fecal samples examined for oocytss of Cryptosporidium spp. (Fig.4), 20 (7.2\%) were found to be positive.

Regarding parasitological contamination of the environment in the study areas, soil samples collected from backyards of pig pens were found to be contaminated with eggs of Ascaris spp. (Table-5).

\section{Discussion}

In this study it was possible to recover eggs and oocysts of gastrointestinal helminths and protozoans, respectively. Twenty seven percent of the pigs were infected with one or more gastrointestinal parasite species. Ascaris suum was the most common helminth in all age categories of pigs examined in the present 
doi: 10.5455/vetworld.2013.433-439

Table-3. Prevalence of intestinal parasites in pigs in Mekelle and Southern Zone of Tigray Region, Ethiopia (2012)

\begin{tabular}{|c|c|c|c|c|}
\hline Study Areas & No. of pigs sampled & Single infection ${ }^{* \#}$ & Mixed infection ${ }^{@}$ & Total No. of Positive \\
\hline Mekelle & 310 & A 83, F 1, E 1 & $4(A \& E)$ & 89 \\
\hline \multicolumn{5}{|c|}{ Urban areas of southern zone of Tigrey region } \\
\hline $\begin{array}{l}\text { Adigudom } \\
\text { Maychew } \\
\text { Alamata } \\
\text { Korem } \\
\text { Mekoni } \\
\text { Total }\end{array}$ & $\begin{array}{c}35 \\
190 \\
139 \\
20 \\
20 \\
714\end{array}$ & $\begin{array}{c}\text { A } 8 \\
\text { A 38, F 3, E } 1 \\
\text { A 30, F } 1, \mathrm{~T} 1, \mathrm{E} 2 \\
\text { A } 7 \\
\text { A } 3\end{array}$ & $\begin{array}{c}\text { 1(A\& F), } 1(A \& E), 1(A \& T) \\
1(A \& F), 1(A \& E) \\
6(A \& F), 3(A \& E) \\
1(A \& T) \\
0\end{array}$ & $\begin{array}{c}11 \\
42 \\
42 \\
8 \\
3 \\
195(27.3 \%)\end{array}$ \\
\hline
\end{tabular}

$\mathbf{A}=$ Ascaris suum, $\mathbf{F}=$ Fasciola hepatica, $\mathbf{E}=$ Eimeria spp., $\mathbf{T}=$ Trichuris suis; $*$ Single infection means, infection of pigs with any one of the parasites; \#For example, in $3^{\text {rd }}$ column it means 83 pigs were infected with Ascaris suum (A), 01 with Fasciola hepatica (F) and 01 with Eimeria spp. (E) and similarly for other rows in the same columns. @Multiple infections mean, pigs infected with more than one parasite.

Table-4. Prevalence of gastrointestinal parasites in different age groups of pigs in Mekelle and urban areas of Southern Zone of Tigray Region, Ethiopia*

\begin{tabular}{lllllllll}
\hline Age groups & \multicolumn{3}{c}{ A. suum } & \multicolumn{3}{c}{ F. hepatica } & \multicolumn{3}{c}{ Eimeria spp.T. suis } \\
& No & $\%$ & No & $\%$ & No & $\%$ & No & $\%$ \\
\hline$<5$ months $(n=340)$ & 71 & 20.9 & 6 & 1.8 & 6 & 1.8 & 0 & 0 \\
$5-12$ months $(n=297)$ & 96 & 32.3 & 6 & 2.0 & 6 & 2.0 & 1 & 0.3 \\
$>12$ months $(n=77)$ & 18 & 23.4 & 1 & 1.3 & 0 & 0.0 & 1 & 1.3 \\
All age groups $(n=714)$ & 185 & 25.9 & 13 & 1.8 & 12 & 1.7 & 2 & 0.3 \\
\hline
\end{tabular}

* Both single and multiple infections were considered to calculate the prevalence

study. This is in agreement with similar studies in extensively managed pigs $[24,25]$. On the contrary, Tiwari et al. [26] reported no evidence of A. suum infection in pigs in Grenada, West Indies. Though, $A$. suum is naturally a parasite of pigs, but it can also infect human [14]. The potential of A. suum to infect human might be due to the fact that it shares similar protein molecules with Ascaris lumbricoides for which man is the natural host $[27,28]$. Therefore, it is not surprising to say extensively managed pigs in the present study areas may act as potential reservoir hosts of human ascariasis.

The prevalence of the second nematode parasite, Trichuris suis, was very low in different age groups of pigs examined. This low prevalence agrees with the findings of earlier studies in Africa and West Indies [26, $29,30]$. This supports the speculations that $T$. suis eggs are highly susceptible to environmental factors. The prevalence of Fasciola hepatica was low (2.81\%) in this study. On the contrary, Apt et al. [31] reported higher prevalence $F$ hepatica in pigs of the Chilean provinces.

Factors such as presence of reservoir hosts, presence of snail intermediate hosts and ability of $F$. hepatica to colonise and adapt new hosts contribute for its spread in livestock in an area [32]. The transmission ecology of our present study areas are not far away from fulfilling the aforementioned epidemiological determinants of fasciolosis in livestock. Mekelle and urban areas of southern zone of Tigray Region are centers of livestock marketing, so that farmers from surrounding rural areas bring livestock to the urban markets. Therefore, such livestock migration from rural villages to markets in the urban areas may contribute for the introduction of gastrointestinal parasites including $F$ hepatica to the urban areas. In addition, there is huge cattle transport to Mekelle from
Table-5. Contamination of soil by eggs of Asacris spp. at backyards of pig pens in the study areas.

\begin{tabular}{lcc}
\hline Study areas & $\begin{array}{c}\text { No. of soil samples } \\
\text { examined }\end{array}$ & $\begin{array}{c}\text { Prevalence of } \\
\text { Ascaris spp.No.(\%) }\end{array}$ \\
\hline $\begin{array}{l}\text { Mekelle Zone } \\
\text { Urban Areas of Southern Zone of Tigray Region }\end{array}$ & $6(75)$ \\
Adigudom & 2 & $02(100)$ \\
Maychew & 10 & $06(60)$ \\
Korem & 1 & $01(100)$ \\
Mekoni & 1 & $0(0)$ \\
Alamata & 3 & $3(100)$ \\
\hline
\end{tabular}

different districts of the region for the Abregele meat factory. Irrigated urban and pre-urban crop production practice through ditching urban wastewater may render suitable habitats for snail intermediate hosts of $F$ hepatica in the present study areas. From our personal observation, pigs in the study areas browse grasses along the irrigation water ditches which may expose them to infection with the metacercaria of $F$ hepatica [33]. This may also contributes for contamination of the ditched water with eggs or oocyts of gastrointestinal parasites contained in pig feces.

The prevalence of Eimeria spp. in this study was much lower than a similar survey in Ethiopia [7] and Zimbabwe [34], respectively. This difference in prevalence of Eimeria spp. may be attributed to the underlining difference in epidemiology of Eimeria spp. in the areas and methods used to recover oocysts from fecal samples.

In the present study, out of 276 pigs examined 20 (7.2\%) were positive for Cryptosporidium spp. This result is consistent with the findings of Morgan et al. [11]. However, the modern Merifluor Cryptosporidium immunofluorescence assay revealed higher positivity of Cryptosporidium spp. in 217 intensively managed pigs in Lusaka, Zambia [35]. Nevertheless previous study by Haileyesus [12] showed prevalence of Cryptosporidium parvum and $C$. hominis in extensively managed cattle and HIV/AIDS patients, respectively in Ethiopia.

There is no statistically significant difference in the prevalence of gastrointestinal parasites (Ascaris suum, Trichuris suis, Fasciola hepatica and Eimeria spp.) in Mekelle and urban areas of southern zone of Tigray Region $\left(\chi^{2}[\mathrm{df} 1]=0.320 ; P=0.572\right)$. This may be due to the reason that pigs of both of the study areas are under similar risk factors of infection with gastrointestinal parasites. During our field survey it was observed that pigs were scavenging on household and 
municipal garbage in both Mekelle and urban areas of southern zone of Tigray Region. Even in few sites of the study areas it was recorded that children were defecating outside to their home and pigs were allowed to feed on children's fecal material. Consumption of human fecal material by pigs may complicate the epidemiology of gastrointestinal parasites such as Ascaris suum and Cryptosporidium spp. that can infect both pigs and man [10].

There was also no statistically significant difference in the prevalence rate of gastrointestinal parasites between male and female pigs $\left(\chi^{2}[\mathrm{df} 1]=\right.$ $1.921 ; P=0.166)$. This result is consistent with the finding of previous study in Holeta, Ethiopia [7]. However, Tamboura et al. [4] reported higher prevalence of gastrointestinal nematodes in female pigs than in males in Burkina Faso. The reason for equal exposure of both sexes of pigs to GIT parasites in the present and previous study [7] in Ethiopia may be due to voracious feeding of both sexes on household and municipal garbage in the study areas.

A significant association was recorded between chances of gastrointestinal parasites infections and different age categories of pigs. It was observed that majority of infection occurring in pigs with ages ranging from 5-12 months ( $\left.\chi^{2}[\mathrm{df} 2]=8.376 ; P=0.015\right)$. On the contrary, Abdu and Gashaw [7] reported statistically insignificant difference in infection rate of gastrointestinal parasites in pigs of different age groups in Holeta, Ethiopia. However, Obonyo et al. [36] reported high prevalence of gastrointestinal infections in finishers than in adults in Kenya. The lower prevalence of gastrointestinal parasites in the youngest ( $<5$ months) and in the oldest ( $>12$ month) age groups might be because, the youngest pigs are lactating and hence partially scavenging on garbage for feed, whereas, most of the oldest pigs were either pregnant females (sows) or males kept for breeding (boars) and therefore were given special attention by the owners in terms of additional feed to reduce their scavenging dependency on garbage which is considered to be one of the risk factors for infection with gastrointestinal parasites.

Eggs of Ascaris spp. were recorded in soil samples collected from backyards of pig pens in the study areas. The reason for the occurrence of eggs of Ascaris spp. in soil may be due to its resistance to environmental factors [37]. Speciation of Ascaris isolates of soil was not possible as eggs of Ascaris suum are morphologically identical to eggs of the human parasite, Asacris lumbricoides. This implies the source of Ascaris egg contamination of soil could be either Ascaris suum or Asacris lumbricoides, which was due to poorly managed pig slurry and outside defecation practices of humans.

\section{Conclusion and Recommendation}

Gastrointestinal parasites (Ascaris suum, Trichuris suis, Fasciola hepatica, Eimeria spp.) and Cryptosporidium spp. have been investigated from extensively managed pigs in Mekelle and southern zone of Tigray Region, Ethiopia. A. suum was most prevalent either as a single or multiple infections with other parasites in pigs examined. The possibilities of Ascaris spp. of pigs to infect man and vice versa coupled with unhygienic environmental condition may complicate the epidemiology and control of ascariasis in the study areas. In the present study extensively managed pigs are also reported to harbor Fasciola hepatica and Cryptosporidium spp. suggesting the potentials of pigs as reservoirs hosts of the parasites. Further investigations are recommended for molecular characterization of Ascaris and Cryptosporidium isolates of pigs to clearly determine the species of the parasites responsible for swine ascariasis and cryptosporidiosis, respectively in the study areas.

\section{Authors' contribution}

ZT was the project leader and designer of the study in addition to drafting and revising the manuscript. EI was responsible for statistical analysis of data, preparation of study area map and edition of the Manuscript. TK was in charge of sample collection and examination. YT was responsible for sample processing. KW rendered overall assistance during sample collection, processing and examination. All authors read and approved the final manuscript.

\section{Acknowledgements}

The authors would like to acknowledge the Department of Biology and College of Veterinary Medicine, Mekelle University, for laboratory facilities. This study received financial support from the MUUMB, Mekelle University. We would like to thank the representatives of veterinary health centers for their unreserved assistance in facilitating the field work. Furthermore, we would like to extend our gratitude to the pig owning households for participation in the study.

\section{Competing interests}

Authors declare that they have no competing interest.

\section{References}

1. Nansen P and Roepstorff A. (1999) Parasitic helminths of the pig: factors influencing transmission and infection levels, International Journal of Parasitology, 29: 877-891.

2. Lekule F.P. and Kyvsgaard N.C. (2003) Improving pig husbandry in tropical resource-poor communities and its potential to reduce risk of porcine cysticercosis, Acta Tropica, 87: 111-117.

3. Nganga C.J., Karanja D.N. and Mutune M.N. (2008) The prevalence of gastrointestinal helminth infection in pigs in Kenya, Tropical Animal Health and Production, 40: 331334.

4. Tamboura H.H., Banga-Mboko H., Maes D., Youssao I., Traore A., Bayala B. and Dembele M.A. (2006) Prevalence of common gastrointestinal nematode parasites in scavenging pigs of different ages and sexes in eastern centre province, Burkina Faso, Onderstepoort Journal of Veterinary Research, 73: 53-60.

5. Permin A, Yelifari L, Bloch P, Steenhard N, Hansen N.P. and Nansen P. (1999) Parasites in cross-bred pigs in the Upper 
East region of Ghana, Veterinary Parasitology, 87: 63-71.

6. Gweba M, Faleke O.O., Junaidu A.U., Fabiyi J.P. and Fajinmi A.O. (2010) Some risk factors for Taenia Solium cystycercosis in semi-intensively raised pigs in Zuru, Nigeria, Veterinaria Italiana, 46: 57-67.

7. Abdu S. and Gashaw A. (2010) Production system dynamism and parasitic interaction of swine in and around Holetta, Ethiopia, Ethiopian Veterinary Journal, 14: 71-81.

8. Uysal H. K., Boral O., Metiner K and Ilgaz A. (2009) Investigation of Intestinal Parasites in Pig Feces That Are also Human Pathogens, Türkiye Parazitoloji Dergisi, 33: 218-221.

9. Ramirez N. E., Ward L. A. and Sreevatsan S. (2004) A review of the biology and epidemiology of cryptosporidiosis in humans and animals, Microbes and Infection, 6: 773-785.

10. Fayer R. (2010) Taxonomy and species delimitation in Cryptosporidium.Experimental, Parasitology, 124:90-97.

11. Morgan U. M., Buddle R, Armson A and Thompson R. C. A. (1999) Molecular and biological characterisation of Cryptosporidium in pigs, Australian Veterinary Journal, 77: 44-47.

12. Haileyesus A. (2010) The prevalence of intestinal parasites and molecular characterisation of Cryptoporidium species in Ethiopia. Ph.D. Thesis, Addis Ababa University, Ethiopia. Pp.117.

13. Hale O. M. and Stewart T. B. (1998) Losses to Internal Parasites in Swine Production, Journal of Animal Sciences, 66: $1548-1554$.

14. Arizono, N., Yoshimura, Y., Tohzaka, N., Yamada, M., Tegoshi, T., Onishi, K. and Uchikawa, R. (2010) Ascariasis in Japan: Is pig-derived Ascaris infecting humans, Japanese Journal of infectious diseases, 63: 447-448.

15. CSA. (2004) Central Statistical Authority. National Statistics Abstract, Addis Ababab, Ethiopia.

16. Kibrom G. (2005) Investigation into engineering properties of Mekele soils with an emphasis on expansive soils, M.Sc. thesis, Addis Abeba University, Addis Ababa, Ethiopia.

17. CSA. (2008) Central Statistical Authority. National Statistics Abstract, Addis Ababab, Ethiopia.

18. Ashebir D., Pasquini M. and Bihon W. (2007) Urban agriculture in Mekelle, Tigray state, Ethiopia: Principal characteristics, opportunities and constraints for further research and development, Cities, 24: 218-228.

19. MZAO. (2011) Mekelle Zonal Agricultural Office. Mekelle, Ethiopia.

20. Araya A. and Stroosnijder L. (2011) Assessing drought risk and irrigation need in northern Ethiopia, Agricultural and forest meteorology, 151:425-436.

21. WHO (1991) Basic laboratory methods in medical parasitology. World Health Organization, Geneva.

22. Bayou K. (2005) Standard veterinary laboratory diagnostic manual. Volume III. Ministry of Agriculture and Rural Development, Animal Health Department. Addis Ababa, Ethiopia.

23. SPSS-10. (1988) SPSS-X user's guide. 3rd ed. Chicago (IL): SPSS Inc.
24. Salifu D.A., Manga T.B. and Onyali, I.O. (1990) A survey of gastrointestinal parasites in pigs of the Plateau and Rivers States, Nigeria, Revue d'Elevage et de Médecine Vétérinaire des Pays Tropicaux, 43(2):193-196.

25. Nsoso S.J., Mosala K.P., Ndebele R.T. and Ramabu S.S. (2000) The prevalence of internal and external parasites in pigs of different ages and sexes in Southeast District, Botswana, Onderstepoort Journal of Veterinary Research, 67: 217-220.

26. Tiwari K. P., Chikweto A, Belot G, Vanpee G, Deallie C, Stratton G and Sharma R.N. (2009) Prevalence of intestinal parasites in pigs in Grenada, West Indies, West Indian Veterinary Journal, 9 (1): 22-27.

27. Alba J. E., Comia M.N., Oyong G. and Claveria F. (2009). Ascaris lumbricoides and Ascaris suum: A comparison of electrophoretic banding patterns of protein extracts from the reproductive organs and body wall, Veterinarski arhiv, 79: 281-291.

28. Leles D, Gardner S. L., Reinhard K, Iñiguez A and Araujo A. (2012) Are Ascaris lumbricoides and Ascaris suum a single species, Parasit Vectors, 5: 42.

29. Esrony K., Kambarage D. M., Mtambo M. M., Muhairwa A. P. and Kusiluka L.J. (1997) Helminthosis in local and crossbred pigs in the Morogoro region of Tanzania, Preventive Veterinary Medicine, 32:41-46.

30. Marufu M.C., Chanayiwa P, Chimonyo M and Bhebhe E. (2008) Prevalence of gastrointestinal nemtodes in Mukota pigs in a communal area of Zimbabwe, African Journal of Agricultural Research, 3(2): 91-95.

31. Apt W., Aguilera X, Vega F, Alcaíno H, Zulantay I, Apt P, González V, Retamal C, Rodríguez J and Sandoval J. (1993). Prevalence of fascioliasis in humans, horses, pigs, and wild rabbits in 3 Chilean provinces, Biol Oficina Sanit Panam, 115: 405-414

32. Mas-Coma S., Bargues M.D. and Valero M.A. (2005) Fascioliasis and other plant-borne trematode zoonoses, International Journal of Parasitology, 35: 1255-1278.

33. PHAO. (2011) Fasciola hepatica: Pathogen safety data sheet - infectious substances. Public Health Agency of Canada. 19 Aug 2011.

34. Chhabra R. C. and Mafukidze R.T. (1992) Prevalence of coccidia in pigs in Zimbabwe, Veterinary Parasitology, 41: $1-5$.

35. Siwila, J. and Mwape, K. E. (2012) Prevalence of Cryptosporidium spp. and Giardia duodenalis in pigs in Lusaka, Zambia, Onderstepoort Journal of Veterinary Research, 79(1): 1-5, Art. \#404, http:// dx.doi.org/10.4102/ojvr. v79i1. 404.

36. Obonyo F. O., Maingi N., Githigia S. M. and Ng'ang'a C. J. (2012) Prevalence, intensity and spectrum of helminths of free range pigs in Homabay District, Kenya. Livestock Research for Rural Development. Volume 24, Article \#48. http://www.lrrd.org/lrrd24/3/obon24048.htm, Retrieved, 27-10-2012.

37. Lewis-Jones R and Winkler M. (1991) Sludge parasites and other pathogens. Ellis Horwood Limited, Chichester, England. 